\title{
Changes in Sink-source Relationships during Shoot Development in Olive
}

\author{
Susanna Marchi' ${ }^{1}$ and Luca Sebastiani \\ BioLabs, Scuola Superiore "Sant'Anna" di Studi Universitari e di Perfezionamento, Piazza Martiri \\ della Libertà 33, I-56127 Pisa, Italy \\ Riccardo Gucci \\ Dipartimento di Coltivazione e Difesa delle Specie Legnose, Università di Pisa, Via del Borghetto 80, \\ I-56124 Pisa, Italy \\ Roberto Tognetti \\ Dipartimento di Scienze Animali, Vegetali e dell'Ambiente, Università degli Studi del Molise, Via De \\ Sanctis, I-86100 Campobasso, Italy
}

AdDitional IndEX words. $\mathrm{CO}_{2}$ assimilation, carbon balance, leaf area, Olea europaea, shoot growth, sink-source transition

\begin{abstract}
Net photosynthesis, dark respiration, chlorophyll and carbohydrate content, and leaf and shoot growth in plants of evergreen olive (Olea europaea L.) grown under controlled conditions were measured to assess changes in carbon balance during leaf development of the 6th, 12th, and 16th node (from the base, first flush) through expansion to maturity. Shoot and leaves expanded in a sigmoid pattern with differences among nodes. Photosynthesis varied with leaf development; young leaves had low $\mathrm{CO}_{2}$ assimilation rates that were reflected in their chlorophyll concentration. Net daily $\mathrm{CO}_{2}$ assimilation was negative in young expanding leaves. The sink-source transition, defined to be the time when the increase in daily carbohydrate exchange rate exceeds the daily increase in leaf carbohydrate content, occurred before full leaf expansion, between $10 \%$ and $30 \%$ expansion depending on the node.
\end{abstract}

Leaves are the main source of $\mathrm{CO}_{2}$ assimilation in plants. The growth of developing leaves initially depends on imported resources (Turgeon and Webb, 1975). Photosynthetic rates are generally low in young expanding leaves and increase up to or slightly after full leaf area expansion; as carbohydrates accumulate, import stops and the export of soluble sugars begins. In early phases of leaf growth, the leaf is a net carbon importer (sink), its growth depending mainly on a supply of imported substances; afterwards it becomes a net carbon exporter (source), its growth depending primarily on its photosynthates. This stage of leaf development may take several days or weeks; leaves of dicotyledonous plants change from sink to source when their area reaches $30 \%$ to $60 \%$ of the final area (Turgeon, 1989).

The capacity of a tissue to import carbohydrates is a measure of its sink strength (Kozlowski, 1992). The position and distribution of leaves along the shoot influences sink strength. The direction of translocation of assimilates varies with the developmental stage of single leaves; fully developed apical leaves export carbohydrates towards younger leaves, basal leaves send carbohydrates to the shoot and roots, intermediate leaves in both directions (Dickson and Isebrand, 1991). Because large amounts of carbohydrates are used in respiration by sinks, absolute growth rate or rate of accumulation of dry matter does not accurately measure the capacity of a sink to receive assimilates. A more appropriate index of actual sink strength is the sum of net carbon gain and respiratory carbon loss. During early stages of leaf growth, synthesis of chlorophyll, proteins and structural compounds is high, resulting in high catabolic rates to support energy need. As the photosynthetic system matures, the requirement for respiratory energy rapidly decreases (Kozlowski, 1992).

Received for publication 8 Oct. 2004. Accepted for publication 27 Nov. 2004 We are grateful to Prof. Jules Janick (Purdue Univ.) for his critical reading of the manuscript.

${ }^{1}$ Corresponding author: phone $+39-050-883070$; fax +39-050-883495; e-mail marchi@ssup.it
In evergreen shrubs of Mediterranean environments, such as olive, shoot growth may not be continuous and a rapid period of shoot elongation may be followed by a summer drought-induced stop, before the next period of growth. Carbon construction costs of evergreen leaves are relatively high (since they are rich in lignin and defensive compounds), though only a small portion of leaves is renewed annually, while remaining leaves are photosynthetically active (Pearcy et al., 1987). Hieke et al. (2002a) found that leaves of litchi (Litchi chinensis Sonn.) expanded in a sigmoid pattern over $50 \mathrm{~d}$ during spring, with net $\mathrm{CO}_{2}$ assimilation increasing from about -4 to $8 \mu \mathrm{mol} \cdot \mathrm{m}^{-2} \cdot \mathrm{s}^{-1}$ as the leaves changed from soft and red, to soft and light green, to hard and dark green; over the same period, dark respiration decreased from 5 to $2 \mu \mathrm{mol} \cdot \mathrm{m}^{-2} \cdot \mathrm{s}^{-1}$.

Leaf longevity and the period for photosynthetic leaf maturation increase with increasing leaf mass to area ratio (Mooney and Gulmon, 1992). Storage of carbon is a major mechanism by which perennial plants are adapted to their environments (Chiariello et al., 1989). Changes in assimilation responses to the environment due to adjustments in carbon balance may result from altered ontogeny or morphological variations associated with increasing leaf age. Changes in sink-source status have not been studied intensively for Mediterranean woody plants. The leaves of olive, which persist for 2 years or more, have high potential for carbohydrate synthesis and storage (Priestley, 1977). Sink-source relationships and the regulation of carbon allocation determine crop yield in plants. To clarify the role of evergreen leaves in source (assimilate availability) and sink (ability to utilize assimilates) limitations to crop yield is warranted in the Mediterranean environment.

The transition from import to export is a function of the development of the photosynthetic systems during leaf ontogeny with the achievement of a net positive carbon balance. In this study, we report on changes in growth, chlorophyll concentration and net $\mathrm{CO}_{2}$ assimilation during shoot development of olive plants 
maintained in growth chamber. In the course of their leaf ontogeny we followed variations in carbohydrate contents for estimating sink-source transition of the 6th, 12th, and 16th layer (first flush). Plantlets were used to test the relationship between development and physiology because growth is confined to a single axis with leaves, stem and roots, without the complications of flowers and fruits. We hypothesized that young leaves would have assimilation potential lower than mature leaves and that differences in the sink-source transition between layers would be reflected in leaf development.

\section{Materials and Methods}

Plant material and growth conditions. Seventy currentyear (harvested from mother plants in August of the previous year), self-rooted cuttings from 'Leccino' olive were grown in 1.5-L plastic pots. All plants were cut in late winter and trained to a single shoot. Pots containing a 1 sphagnum peat : 1 pumice (v/v) were watered regularly to field capacity. Plants were grown in a growth chamber (maximum photosynthetic active radiation $400 \mu \mathrm{mol} \cdot \mathrm{m}^{-2} \cdot \mathrm{s}^{-1}$, night-day temperature increasing with the season from $19-23$ to $23-27^{\circ} \mathrm{C}$, relative humidity $60 \%$ to $70 \%$, photoperiod $15 \mathrm{~h}$ light $/ 9 \mathrm{~h}$ dark; light and temperature changed gradually). At the beginning of leaf area expansion (early March) plants were fertilized with 50 mL half-strength Hoagland solution; the treatment was repeated approximately every $15 \mathrm{~d}$ throughout the experiment. Plants were controlled for pests and manually weeded. Plants were subdivided in 10 control and 60 experimental individuals, and the latter sorted in 20 plants for each layer in order to cover the whole leaf expansion interval.

GrowTH ANALYSIS. Shoot length, number of layers (node from the base) and area of all leaves were monitored on 10 control plants approximately every $10 \mathrm{~d}$, throughout the experimental period. The area of single leaves at the 6th, 12th, and 16th layer was also periodically measured. The growth of shoots and leaves was expressed as a function of time by a logistic equation fitted for each plant:

$$
y=\frac{a}{1+\left(\frac{x}{c}\right)^{b}}
$$

where $x$ indicates the time in days from unfolding, and $a, b$, and $c$ are constants defining the shape of the response. The asymptote $a$ was fixed equals to the maximum shoot length or leaf area $(\mathrm{cm}$ and $\mathrm{cm}^{2}$, respectively, carrying capacity of the environment), reached when the last three measurements were alike; $b$ is the width of the gradual transition from low to high values (dimensionless units, curvature of the growth pattern); $c$ represents the value (days, curve displacement along the $x$-axis) in which the function is halfway of its width (inflection point at which the growth rate reaches its maximum value). In the case of area expansion of a single leaf, the asymptote was fixed at 100 (full leaf expansion in percentage). This model was fitted to the data by the iterative process of the Marquardt-Levenberg algorithm (SigmaPlot; Jandel Scientific, San Rafael, Calif.). This equation was used for extrapolating back leaf age of experimental plants, through their area.

The cords of each leaf (lamina length, $L$, and lamina width, $l$ ) were measured and converted to leaf area after calibration $(y=$ $0.7358 x+0.1417, n=81, r^{2}=0.99$; where $y$ is leaf area and $x$ is $L \times l)$. This curve $(P<0.0001)$ was established from preliminary destructive leaf sampling and measurement of leaf area with a planimeter (LI-3000; LI-COR, Lincoln, Nebr.).

Variations in growth rate of leaves over the course of their individual surface expansion and of shoots during their individual length development was smoothed and expressed logarithmically:

$R_{\mathrm{G}}$ (relative change in shoot length-leaf area) $=\left(\operatorname{lng}_{2}-\operatorname{lng}_{1}\right) /\left(t_{2}-t_{1}\right)$

in which $\mathrm{G}$ is leaf area or shoot length, respectively, and $t$ is time of leaf or shoot emergence $(t=0)$.

Chlorophyll Concentration. Total chlorophyll was estimated with a portable chlorophyll meter (SPAD-502; Minolta Camera Co., Osaka, Japan) on leaves of olive, during the course of experiment. Data were converted into total concentration of chlorophyll per unit leaf area using a calibration curve $(y=0.0136 x$ $-0.3416, n=32, r^{2}=0.76$, where $x$ is the SPAD value and $y$ the chlorophyll concentration). This regression $(P<0.0001)$ was established from preliminary destructive leaf sampling, chlorophyll extraction in $N, N$-dimethylformamide and spectrophotometer determinations (Lambda 6 UV-VIS; Perkin-Elmer, Bucks, U.K.) according to Moran (1982). Chlorophyll content (on leaf area and dry mass basis) was monitored during shoot development on control plants (6th layer) and on plants used for carbon balance analysis (6th, 12th, and 16th layer).

Photosynthesis and Respiration. Photosynthesis and respiration measurements were made on attached leaves at the 6th, $12 \mathrm{th}$, and 16th layer, at different rates of surface expansion, with a portable gas exchange system (LI-6400; LI-COR) equipped with a red-blue LED source (6400-02B). Photosynthetic rate $(A)$ and dark respiration $(R$, at the end of the dark period) were measured on 20 plants of each 6 th, 12th, and 16th layer. We first measured the rate of dark respiration (mitochondrial) after shading the cuvette with aluminum cover, because the rate of dark respiration would increase with accumulation of photosynthetates (Noguchi et al. 1996). Dark respiration was extrapolated to different temperatures using a $Q_{10}$ relation as follows:

$$
R=R_{\mathrm{n}} Q_{10}^{(T-T \mathrm{n}) / 10} \quad\left(Q_{10}=2.2\right)
$$

where $T_{\mathrm{n}}$ is the leaf temperature at which $R_{\mathrm{n}}$ was measured and $T$ the leaf temperature at which $R$ was calculated. For Mediterranean climates, $Q_{10}$ is expected to be around 2.2 (Larcher, 1983); in addition, the small size of cuttings should have prevented $Q_{10}$ from changing during the experiment. Potential light-induced limitations in mitochondrial respiration were considered of limited quantitative importance in the calculation, though may amount to $50 \%$ in evergreen shrubs (Villar et al., 1994) such as olive. Then plants were measured in duplicate (each leaf sampled twice and measurements averaged) for daily courses of gas exchange between the leaf and the atmosphere, every 2-3 h, from Mar. to Sept. 2003. The light source enabled for changing photosynthetic photon flux density (PPFD) in seven steps (from a minimum of 200 to a maximum of $800 \mu \mathrm{mol} \cdot \mathrm{m}^{-2} \cdot \mathrm{s}^{-1} P P F D$, well above saturation). Cuvette conditions during measurements resembled open environment for the period; average temperatures were $20-28^{\circ} \mathrm{C}$ and relative humidity ranged $45 \%$ to $65 \%$.

DRY MASS AND CARBON CONTENT. After gas exchange measurements plants were harvested and the aboveground part separated into shoot and leaves. The shoot and the leaves were oven-dried at $65{ }^{\circ} \mathrm{C}$ until constant weight, and then they were weighed for subsequent analysis. 
Ash concentration was determined after combustion of the sample (individual leaves) in a muffle furnace for $5-6 \mathrm{~h}$ at 550 ${ }^{\circ} \mathrm{C}$. The gravimetric difference between biomass weight and corresponding ash concentration was considered equivalent to total leaf carbohydrate content $\left(\mathrm{CH}_{2} \mathrm{O}\right)$; the organic nitrogen content volatilized during combustion was considered negligible to our purposes. Nitrogen content ranged $2 \%$ to $4 \%$, but did not change markedly through stages of leaf development (Marchi, 2004); leaf sulphur content varied between $0.1 \%$ and $0.5 \%$ (L. Sebastiani, personal communication).

Estimation of SINK-SOURCE TRANSITION. The sink-source transition of the leaf has been determined following Turgeon and Webb (1975) and Miyazawa et al. (2003). To estimate the leaf expansion when sink-source transition of $\mathrm{CH}_{2} \mathrm{O}$ occurs the daily exchange rate of $\mathrm{CO}_{2}$ for each measured leaf and the increment in weight of $\mathrm{CH}_{2} \mathrm{O}$ needed for growth of leaf surface on a time basis were calculated. The age of expanding leaves used for measurements was estimated from their length and width (area) using the logistic equation of the plant.

The daily $\mathrm{CO}_{2}$ exchange rate was obtained by subtracting nighttime $\mathrm{CO}_{2}$ loss by respiration from daytime $\mathrm{CO}_{2}$ gain by photosynthesis (derived from gas exchange measurements). For estimating daytime $\mathrm{CO}_{2}$ assimilation gain by photosynthesis, we plotted the diurnal photosynthetic course from dawn to dusk and integrated the area below, for each measured leaf; photosynthetic rates at dawn and at dusk were considered equal to zero. To estimate nighttime $\mathrm{CO}_{2}$ loss by respiration, dark respiration rate was multiplied by the period in which $P P F D$ was zero; the dark respiration rate was assumed to be constant during the night. To convert daily assimilation rate from $\mu \mathrm{mol} \cdot \mathrm{m}^{-2} \cdot \mathrm{d}^{-1}$ to $\mathrm{g} \cdot \mathrm{d}^{-1}$ per leaf, values were multiplied by 30 (considering the atomic weight of $\mathrm{C}, \mathrm{H}$, and $\mathrm{O}$ ) and divided by $10^{6}$ and then scaled to leaf area.

In the interval considered, the amount of $\mathrm{CH}_{2} \mathrm{O}$ (derived from gravimetric differences as above described) needed for the expansion of leaf lamina was found to increase linearly with leaf age (and then with the percentage of leaf expansion). The slope of the regression that describes the relationship between $\mathrm{CH}_{2} \mathrm{O}$ content and leaf age represents the relative increment of $\mathrm{CH}_{2} \mathrm{O}$ per unit of time. The leaf age when the sink-source transition occurs corresponds to the intersection of the daily $\mathrm{CH}_{2} \mathrm{O}$ exchange rate with the derivate (slope) of the daily increase in leaf $\mathrm{CH}_{2} \mathrm{O}$ content.

Statistical analysis. Plants were assembled in a completely randomized design. All data were averaged on a plant basis and individual means used for statistical analysis. One-way analysis of variance (ANOVA) for plant parameters was performed. Statistical analysis was conducted using Statistica statistical package (StatSoft, Tulsa, Okla.). Separation of means was performed using an LSD test, at the 0.05 significance level. Fitting the logistic equations (with the least squares method) and linear regressions were performed with SigmaPlot software (Jandel Scientific). The cessation date of leaf area expansion was defined as the date when more than $99 \%$ of the maximum leaf area was reached on the logistic equation. The slope and elevation of regression lines were tested for homogeneity of error and coefficients were compared for significance, Student's $t$ test.

\section{Results}

Maximum shoot length (asymptote $a$ averaged for all logistic functions) was reached after $105 \mathrm{~d}$ (late June; $27.3 \pm 1 \mathrm{~cm}$ ). The empirical growth model fitted the data well (Fig. 1A-B). A higher
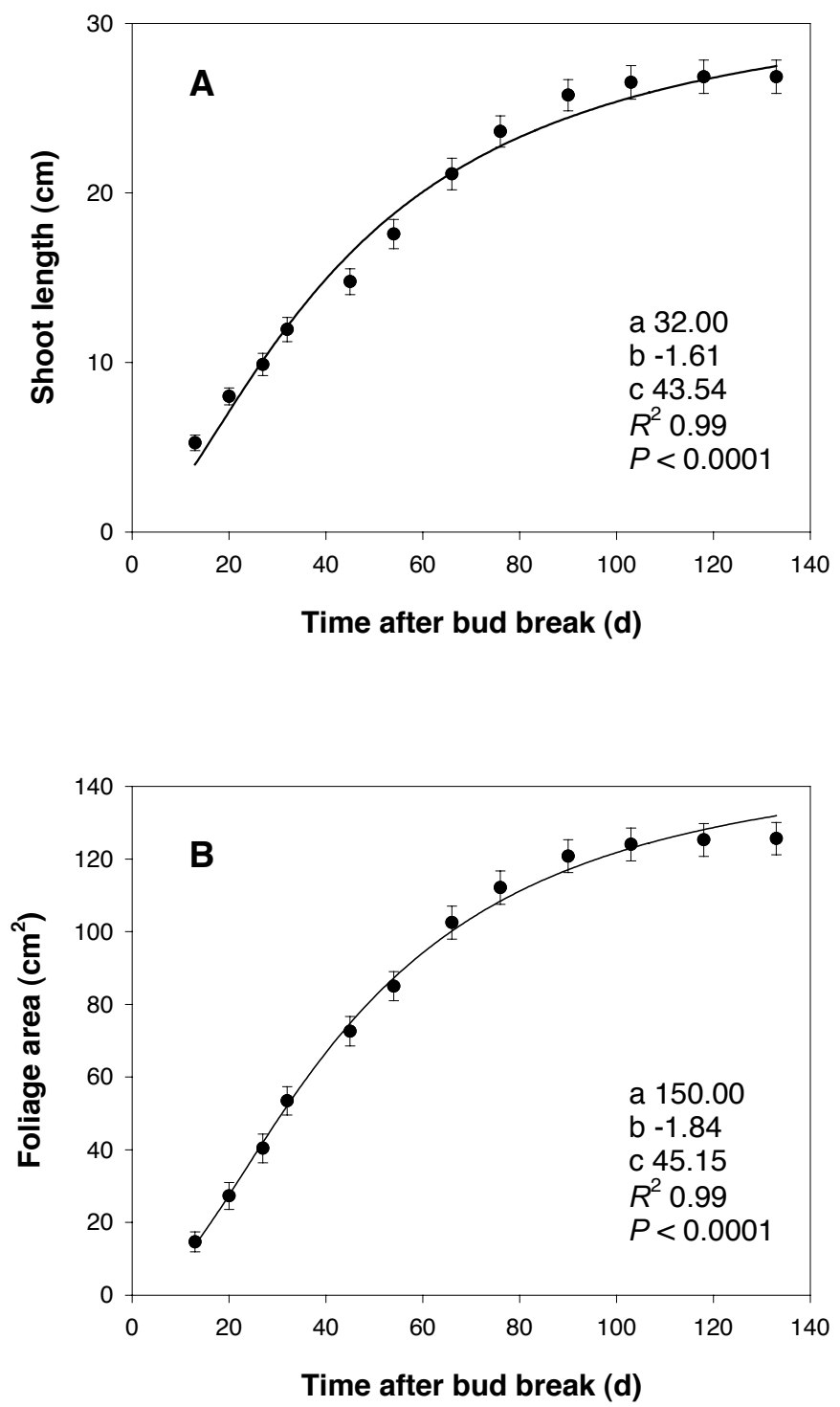

Fig. 1. Changes in shoot length (A) and foliage area $(\mathbf{B})$ with time in control plants of Olea europaea. Data are the means ( $\pm \mathrm{SE}$ ) of 10 plants. Logistic equations were fitted to the data with a nonlinear least squares method. Regression parameters and significance of averaged functions are also reported in the frame. Averaged values of parameters of single functions for each plant are reported in the text.

absolute value of the coefficient $b$ (dimensionless units) indicates that the shoot reached maximum length (or leaf area, see below) more rapidly, while a smaller value of the coefficient $c$ (days) indicates earlier completion of shoot growth (or leaf area). Averaged values for the coefficient $b$ and for the coefficient $c$ were $-2.1 \pm 0.07$ units and $35.19 \pm 1.43 \mathrm{~d}$, respectively (shoot length). Foliage area of the entire shoot attained maximum values of 128.5 $\pm 4.5 \mathrm{~cm}^{2}$ (March-July), following the logistic function. Averaged values for the coefficient $b$ and for the coefficient $c$ were $-2.48 \pm$ 0.1 units and $37.5 \pm 1.32 \mathrm{~d}$, respectively (foliage area).

Maximum relative growth rate was observed in mid-March $\left(0.04 \mathrm{~cm} \cdot \mathrm{cm}^{-1} \cdot \mathrm{d}^{-1}\right.$ and $0.11 \mathrm{~cm}^{2} \cdot \mathrm{cm}^{-2} \cdot \mathrm{d}^{-1}$ for shoot length and foliage area, respectively), and then values decreased rapidly during the season (Fig. 2A-B).

The 6th, 12th, and 16th layer reached full surface expansion in 50-60 d from unfolding, ceasing growth in early July (Fig. $3 \mathrm{~A}-\mathrm{C}$ ) when averaged maximum leaf area was 9.43, 9.02, and 

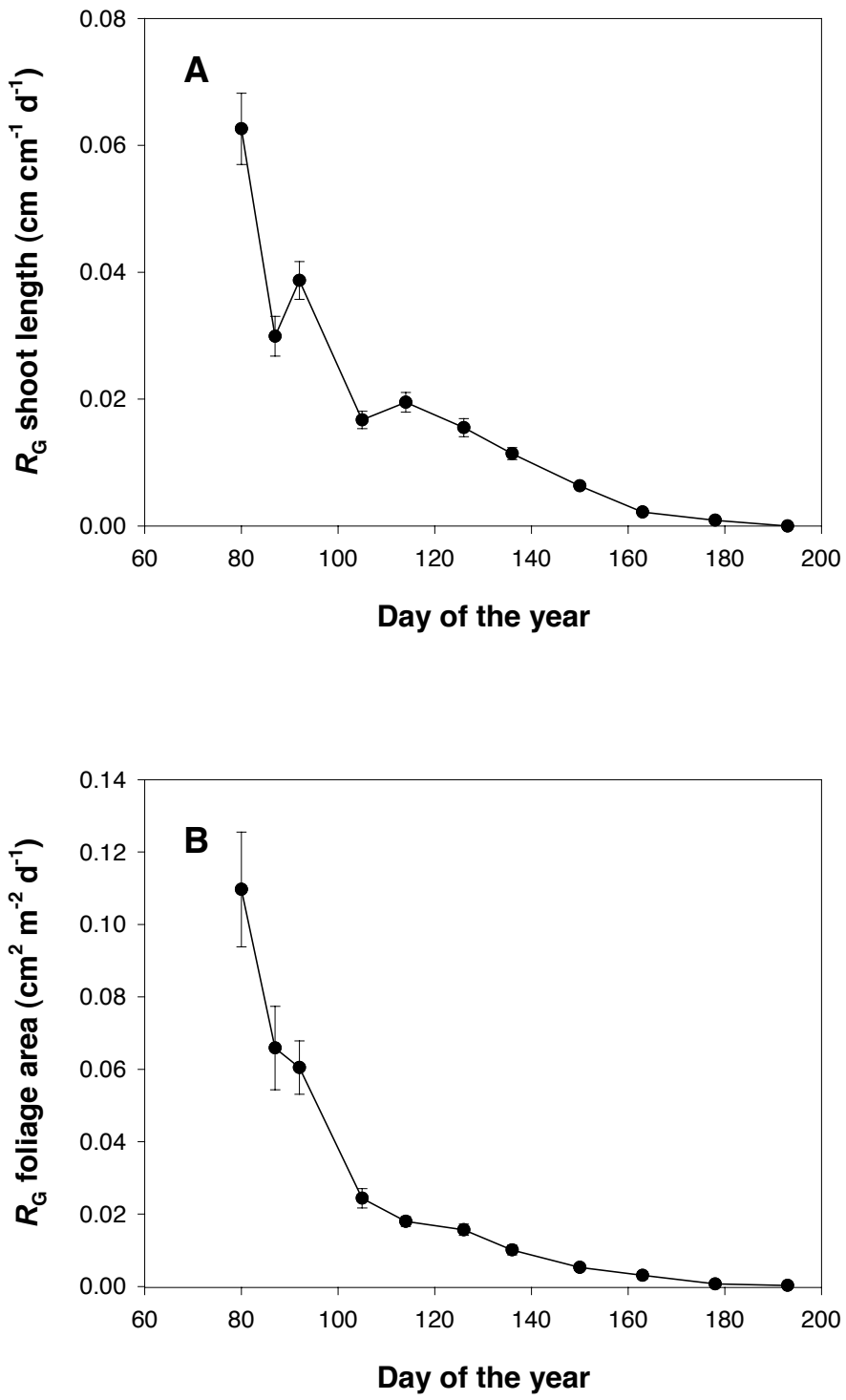

Fig. 2. Relative changes in shoot length (A) and foliage area (B) (relative growth rate, $R_{\mathrm{G}}$ ) during the growing season in control plants of Olea europaea. Data are the means $( \pm$ SE) of 10 plants.

$9.62 \mathrm{~cm}^{2}$, respectively. Values for coefficient $b$ never differed significantly between nodes (Table 1) (asymptote $a$ being fixed at $100 \%$, estimated on control plants the previous year). The coefficient $c$ was significantly lower for the 6th than the 12th and 16th layer.

Total chlorophyll concentration, increased linearly with leaf expansion across all nodes, on both an area (Fig. 4A) and a dry mass (Fig. 4B) basis. In control plants (6th layer), total chlorophyll concentration increased in the first $60 \mathrm{~d}$ of leaf development (data not shown), and then leveled off on averaged values of $1.45 \mathrm{~g} \cdot \mathrm{m}^{-2}$.

Net daily $\mathrm{CO}_{2}$ assimilation ( $24 \mathrm{~h}$ ) augmented with increasing leaf area expansion in all nodes. The net $\mathrm{CO}_{2}$ assimilation for a 24-h period did not increase linearly with leaf expansion (Fig. $5 \mathrm{~A}-\mathrm{C})$; the increase in net daily assimilation was linear in the range $8 \%$ to $36 \%, 10 \%$ to $52 \%, 9 \%$ to $38 \%$ of full leaf area expansion (best fit), respectively for the 6th, 12th, and 16th layer, and the compensation expansion was estimated by fitting a linear regression to these data only. The compensation expansion (that is
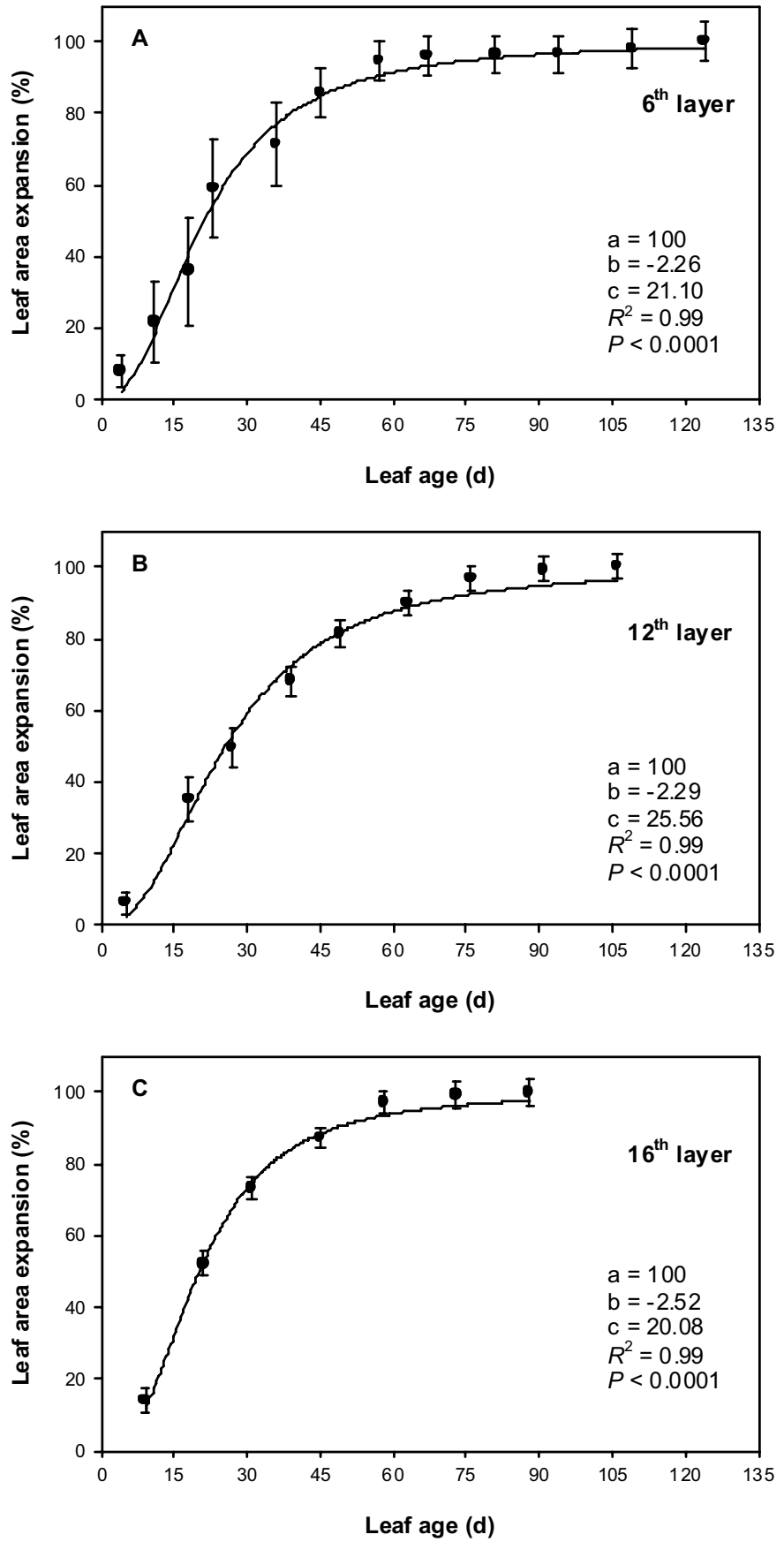

Fig. 3. Changes in percentage of leaf area expansion with leaf age (6th, 12th, and 16th layer; A, B, C) in plants of Olea europaea. Data are the means ( $\pm \mathrm{SE})$ of 10 plants. Logistic equations were fitted to the data with a nonlinear least squares method. Regression parameters and significance of averaged functions are also reported in the frame. Averaged values of parameters of single functions for each plant and significance are reported in Table 1.

the percent of maximum leaf area at which nighttime respiration balances daytime photosynthesis so that net assimilation is zero) was considered equivalent to the point where the regression line met the $x$-axis passing through zero. Net daily assimilation of the 6 th layer was close to zero until $\approx 20 \%$ of full leaf area expansion, and then rapidly increased up to a steady plateau between 200 and $400 \mathrm{mmol} \cdot \mathrm{m}^{-2} \cdot \mathrm{d}^{-1}$. The 12 th layer was characterized by positive values of net daily assimilation from the very beginning of leaf expansion. Net daily assimilation of the 16th layer was positive starting from $13 \%$ of full leaf area expansion. The compensation 
Table 1. Coefficients of the logistic function fitted to the data for percentage of area expansion of single leaves at the 6th, 12th, and 16th node of Olea europaea. Values are the mean \pm SE $(n=10)$. The asymptote $a$ is fixed at $100 \%$; $b$ is the width of the gradual transition from low to high values (dimensionless units); $c$ represents the value (days) in which the function is $50 \%$ of its width. The level of significance (ANOVA) is reported; different letters within the same column indicate significant differences between nodes at $P \leq 0.05$ (LSD).

\begin{tabular}{lcc}
\hline Layer & $b$ & $c$ \\
\hline 6th & $-2.64(0.32)$ & $13.76(1.92) \mathrm{a}$ \\
12th & $-2.25(0.19)$ & $26.29(2.48) \mathrm{b}$ \\
16th & $-2.42(0.17)$ & $20.55(1.11) \mathrm{b}$ \\
ANOVA & & \\
$P$ level & 0.5357 & 0.0005
\end{tabular}

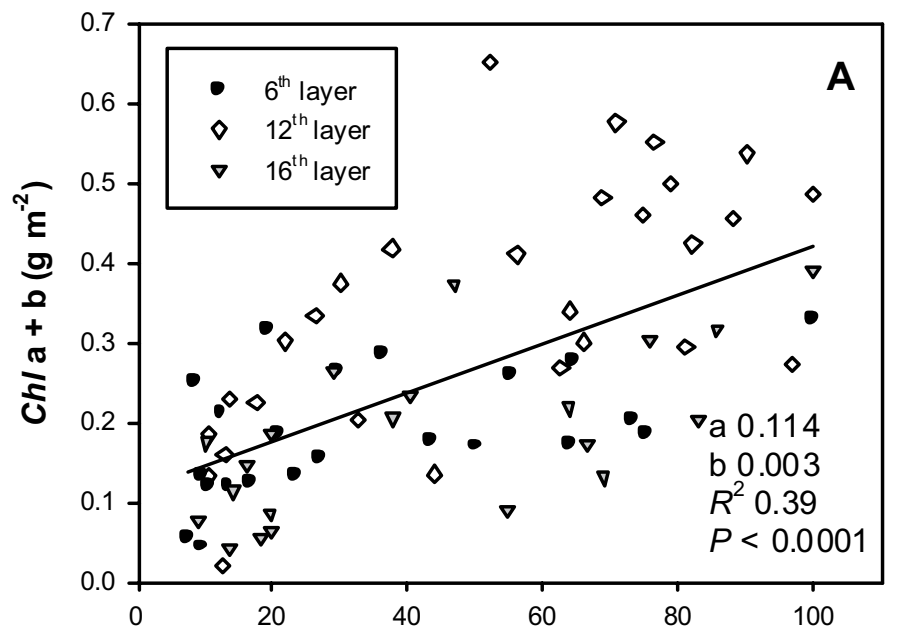

Leaf area expansion (\%)

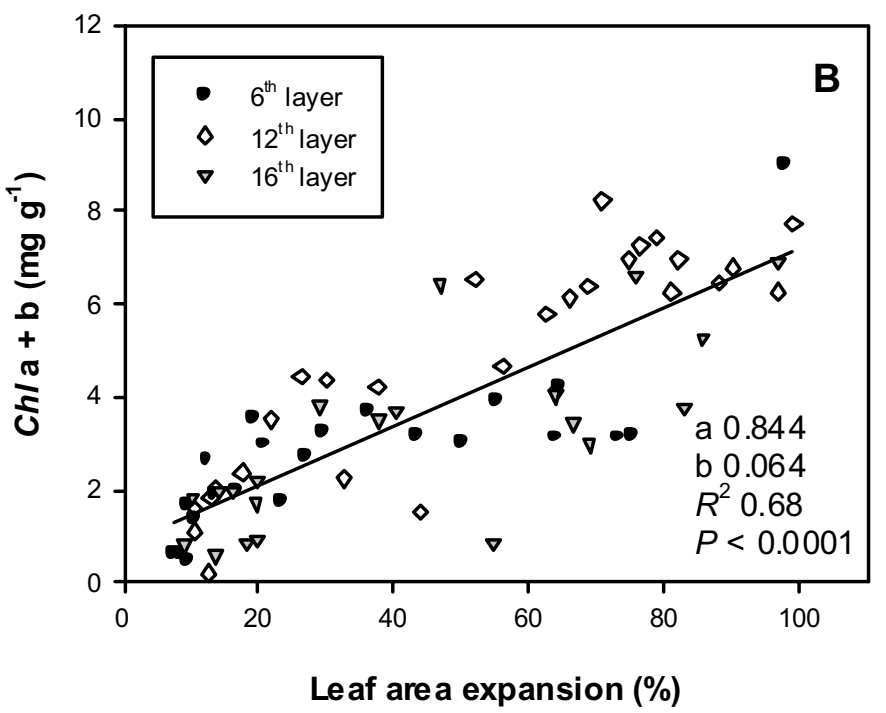

Fig. 4. Relationships between total chlorophyll content $(\mathrm{Chl} \mathrm{a}+\mathrm{b})$ on area (A) or dry mass (B) basis and percentage of leaf area expansion in plants of Olea europaea (6th, 12th, and 16th node). Regression parameters and significance are also reported in the frame.
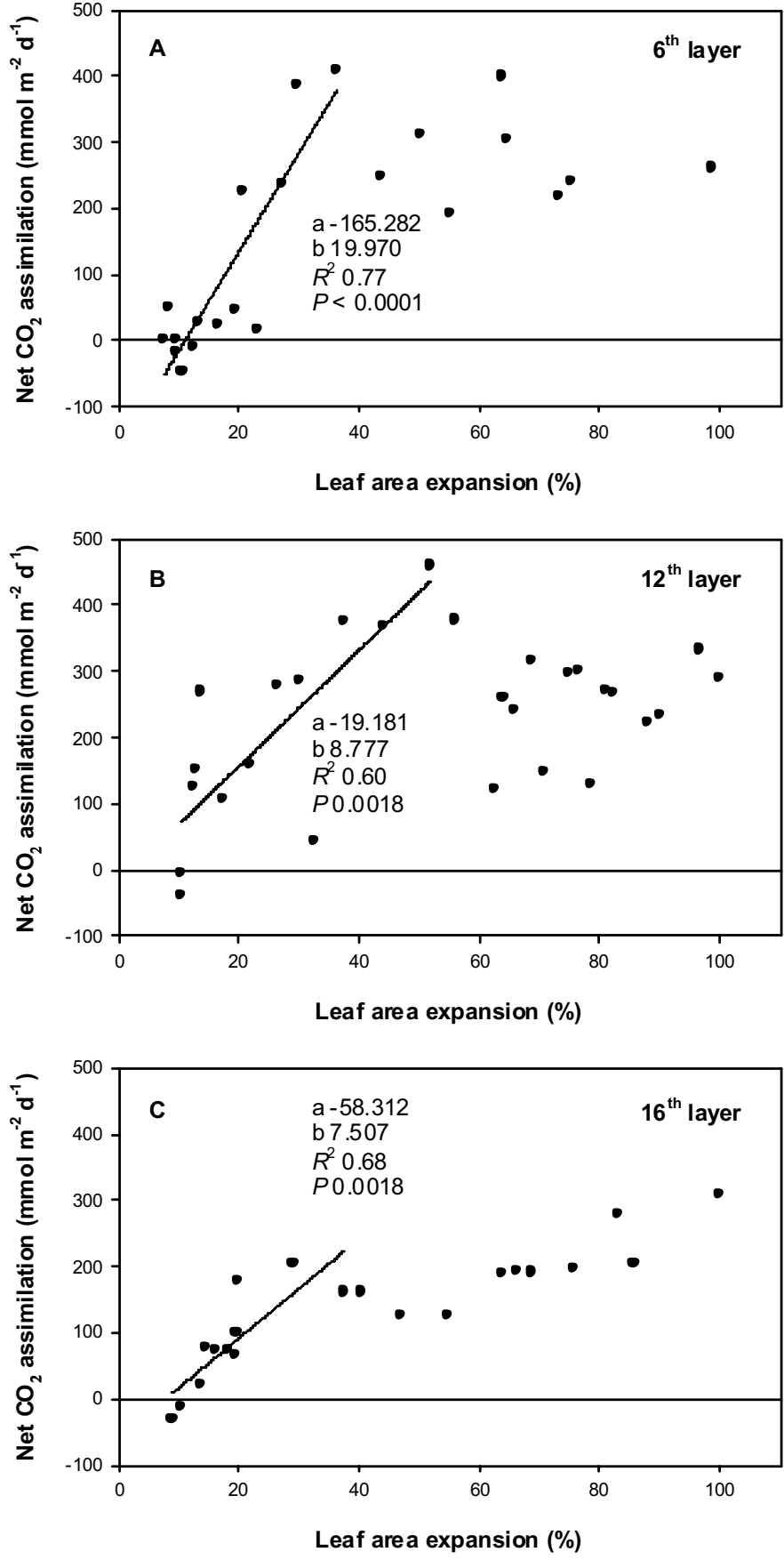

Fig. 5. Changes of daily net $\mathrm{CO}_{2}$ assimilation (subtracting nighttime $\mathrm{CO}_{2}$ loss by respiration from daytime $\mathrm{CO}_{2}$ gain by photosynthesis) with leaf area expansion (6th, 12th, and 16th layer; A, B, C) in plants of Olea europaea. The linear regression fitted the data in the interval $8 \%$ to $36 \%, 10 \%$ to $52 \%, 9 \%$ to $38 \%$ (best fit), respectively for the 6th, 12 th, and 16th layer; the intersection with $x$-axis passing through zero represents the compensation point of leaf area expansion. Regression parameters and significance are also reported in the frame. 
expansion was achieved when the 6th and 16th layer reached $10 \%$ to $11 \%$ of full leaf area expansion, respectively corresponding to 1.07 and $1.02 \mathrm{~cm}^{2}$, while the 12th layer at $\approx 2 \%\left(0.197 \mathrm{~cm}^{2}\right)$.

The sink-source transition for total $\mathrm{CH}_{2} \mathrm{O}$ in the leaf was defined as the point where the regression line of daily increase in total $\mathrm{CH}_{2} \mathrm{O}$ assimilation met the straight line of increase in total $\mathrm{CH}_{2} \mathrm{O}$ content per unit time. A linear regression was fitted forced through the origin between leaf age (estimated through the logistic equation) and total $\mathrm{CH}_{2} \mathrm{O}$ content (dry mass minus ash weight) for each layer. The leaf was considered sink when total daily $\mathrm{CH}_{2} \mathrm{O}$ assimilation was less than the lower limit of confidence interval and source if more than the upper boundary (Table 2). The 6th layer began to export $\mathrm{CH}_{2} \mathrm{O}$ after about $14 \mathrm{~d}$ from unfolding (corresponding to $27 \%$ to $30 \%$ of full leaf area expansion), after $10-12$ d ( $10 \%$ to $14 \%$ of full expansion) the 12 th layer and after $\approx 13 \mathrm{~d}$ ( $21 \%$ to $29 \%$ of full expansion) the 16th layer (Fig. 6A-C).

\section{Discussion}

The developing shoots (length) and leaves (total and single area) of olive followed the logistic growth model. In the model, a higher value of coefficient $b$ indicates that growth has a latent period at first (slower growth) then a steep phase, attaining more rapidly maximum values; whereas a lower value of coefficient $c$ indicates earlier completion of shoot or leaf growth. Olive did not show a latent phase and accomplished rapidly $50 \%$ of shoot growth (stem growth and foliage expansion). In deciduous species, vegetative and reproductive organs compete for available resources in the early season before completion of adequate photosynthesizing surface, whereas, the sclerophyllous olive has prompt growth resumption when temperatures are mild and soil moisture is still abundant.

The coefficient $b$ remained constant across the three layers, while coefficient $c$ increased from the 6 th to the 12 th and the 16 th layer. Miyazawa et al. (1998, 2003) and Miyazawa and Terashima (2001) reported a sigmoid pattern for leaf expansion in evergreen broad-leaved trees and herbaceous species, which showed a steep growth without a marked latent phase. Hieke et al. (2002a, 2002b) used a sigmoid function for describing shoot and leaf development in the tropical evergreen litchi, which showed a latent phase at the early stage followed by an exponential growth; leaves of other tropical fruit trees, such as avocado (Persea americana Mill.), had similar behavior to litchi (Schaffer et al., 1991).

Chlorophyll content increased with leaf expansion, though more clearly on dry mass basis than on area basis (leaf mass per area ratio in olive did not increase noticeably with leaf expansion, data not shown). Gas exchange and $\mathrm{CO}_{2}$ assimilation followed chlorophyll synthesis, as reported for tropical evergreen species (Hiecke et al., 2002a; Ni et al., 1995; Schaffer et al., 1991; Schaper and Chacko, 1993). However, olive leaves reached photosynthetic maturity (chloroplast development) relatively early; this behavior may represent an advantage in Mediterranean environments, wherein this species has to overcome recurrent hot and dry summers.

Net daily $\mathrm{CO}_{2}$ assimilation was negative in the earlier stages of development, regardless of the node, because $\mathrm{CO}_{2}$ respired during the night in young leaves exceeded that assimilated during the day. The daily balance of $\mathrm{CO}_{2}$ was positive at percentages of leaf area expansion fairly low; $10 \%$ of leaf development $(8 \mathrm{~d}$ from unfolding) for the 6th layer, $2 \%$ (soon after unfolding) for the 12 th layer, and $11 \%$ ( $9 \mathrm{~d}$ from unfolding) for the 16 th layer
Table 2. Coefficients of the linear regression forced through the origin fitted between leaf age (from initiation, estimated through the logistic equation) and total $\mathrm{CH}_{2} \mathrm{O}$ content (dry mass minus ash weight), for the 6 th, 12 th, and 16 th node of Olea europaea; slope (b), confidence interval $( \pm 95 \%)$, coefficient of determination $\left(R^{2}\right)$, and significance level $(P)$.

\begin{tabular}{lccccc}
\hline Layer & $b$ & $-95 \%$ & $+95 \%$ & $R^{2}$ & $P$ \\
\hline 6th & 0.00113 & 0.00102 & 0.00124 & 0.83 & $<0.0001$ \\
12th & 0.00098 & 0.00088 & 0.00109 & 0.73 & $<0.0001$ \\
16th & 0.00099 & 0.00081 & 0.00111 & 0.83 & $<0.0001$ \\
\hline
\end{tabular}
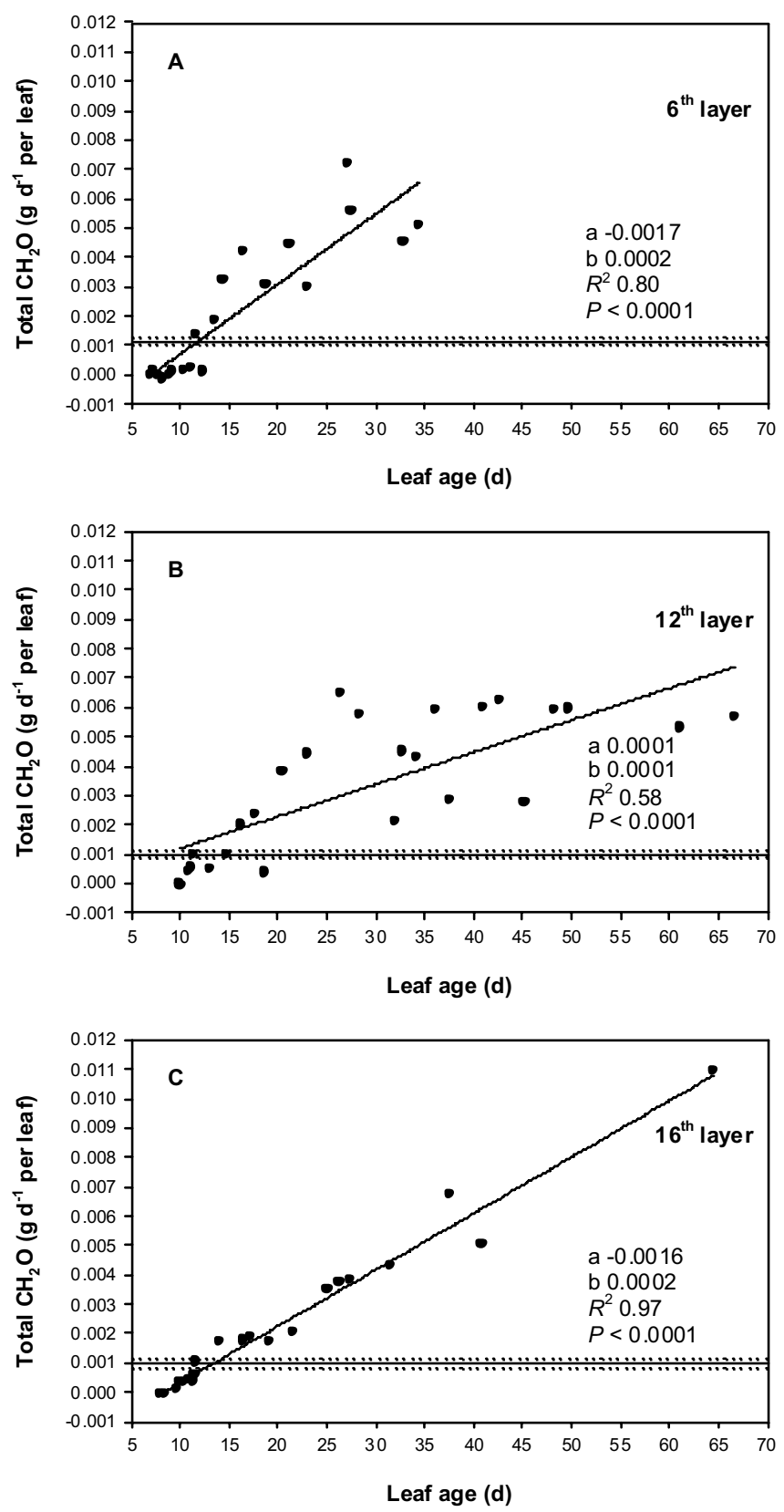

Fig. 6. Changes of daily total carbohydrate $\left(\mathrm{CH}_{2} \mathrm{O}\right)$ assimilation with leaf age (6th, 12th, and 16th layer; $\mathbf{A}, \mathbf{B}, \mathbf{C})$ in plants of Olea europaea. All data were fitted by a linear regression forced through the origin, whose intersection with the derivate (slope) of the daily increase in leaf carbohydrate content (symbolized by the line parallel to the $x$-axis; dotted lines stand for \pm confidence interval, see Table 2) represents the sink-source transition. Regression parameters and significance are also reported in the frame. 
(the same behavior was observed for the 6th layer the previous year, data not reported). Differences between layers are probably due to the higher net daily $\mathrm{CO}_{2}$ assimilation at the beginning of leaf expansion and/or to the higher variability as observed for the 12th in comparison to the 6th and 16th layer. These values are lower than those reported for a typical evergreen fruit tree by Hieke et al. (2002a); in litchi net $\mathrm{CO}_{2}$ assimilation became positive when leaves reached $50 \%$ of final area (30 d from emergence) and peaked after leaves were fully expanded.

The olive leaf began to be net exporter of assimilates at a percentage of leaf expansion relatively low; the sink-source transition was not clearly affected by the leaf position along the shoot. Such a behavior could be due to the low daily increment in $\mathrm{CH}_{2} \mathrm{O}$ needed for leaf growth. Olive leaves grow slowly, in terms of mass increment, and with a low surface area, thus the total amount of assimilates produced by the single leaf is also small (despite the high leaf mass per unit area). The sink-source transition in the three layers was strictly related to the maximum photosynthetic capacity reached by the leaves. In terms of effective leaf area, the sink-source transition was attained at 2.8, 1.26, and $2.78 \mathrm{~cm}^{2}$, respectively for the $6 \mathrm{th}, 12 \mathrm{th}$, and 16 th layer. The sink-source transition began when leaf lamina of all layers was rapidly expanding. Nevertheless, this shift occurred when the relative growth rate of single leaves (data not shown) was in the descending phase. Turgeon and Webb (1973) observed a similar trend in leaves of pumpkin (Cucurbita pepo L.), in which at transition point from import to export the relative growth rate of the lamina has decreased considerably. Expanding leaves may take advantage in having the import-export transition only when the relative growth rate has started decreasing since rapidly developing tissues require a constant supply of nutrients.

The specific carbon economy of growing shoots in olive might be related to the peculiar habitat of origin. During leaf area expansion, there could be competition for nutrients between cell division (structure) and chloroplast development (function) because both processes would require large amounts of nitrogen (Miyazawa et al., 2003). The synchronicity of these processes in expanding leaves might be altered by limited soil water availability limiting root nitrogen uptake and subsequent transport to foliage. The specific transition pattern might be related to distinct drought avoidance strategies; natural selection eventually amends leaf investment strategies and traits that are not competitive. Further studies warrant clarifying whether differences in sink-source transition between deciduous species and olive co-occurring in Mediterranean-type agro-ecosystems may be modeled implementing plant and climatic data, and weighing the relative importance of structural and functional characters.

\section{Literature Cited}

Chiariello, N.R., H.A. Mooney, and K. Williams. 1989. Growth, carbon allocation and cost of plant tissues, p. 327-365. In: R.W. Pearcy, J.R. Ehleringer, H.A. Mooney, and P.W. Rundel (eds.). Plant physiological ecology. Chapman and Hall, New York.

Dickson, R.E. and J.G. Isebrand. 1991. Leaves as regulators of stress responses, p. 3-34. In: H.A. Mooney, W.E. Winner, and E.J. Pell (eds.). Response of plants to multiple stresses. Academic, San Diego.

Hieke, S., C.M. Menzel, and P. Lüdders. 2002a. Shoot development, chlorophyll, gas exchange and carbohydrates in lychee seedlings (Litchi chinensis). Tree Physiol. 22:947-953.

Hieke, S., C.M. Menzel, and P. Lüdders. 2002a. Effects of leaf, shoot and fruit development on photosynthesis of lychee trees (Litchi chinensis). Tree Physiol. 22:955-961.

Kozlowski, T.T. 1992. Carbohydrate sources and sinks in woody plants. Bot. Rev. 58:107-222.

Larcher, W. 1983. Physiological plant ecology. Springer-Verlag, Berlin.

Marchi, S. 2004. Cambiamenti nelle caratteristiche strutturali e funzionali della foglia e relazioni source-sink durante lo sviluppo del germoglio in una specie arborea decidua (Prunus persica) ed in una sempreverde (Olea europaea). PhD Diss., Univ. of Pisa. p. 160.

Miyazawa, S.I, S. Satomi, and I. Terashima. 1998. Slow leaf development of evergreen broad-leaved tree species in Japanese warm temperate forests. Ann. Bot. 82:859-869.

Miyazawa, S.I. and I. Terashima. 2001. Slow development of leaf photosynthesis in an evergreen broad-leaved tree, Castanopsis sieboldii: Relationships between leaf anatomical characteristics and photosynthetic rate. Plant Cell Environ. 24:279-291.

Miyazawa, S.I., A. Makino, and I. Terashima. 2003. Changes in mesophyll anatomy and sink-source relationships during leaf development in Quercus glauca, an evergreen tree showing delayed leaf greening. Plant Cell Environ. 26:745-755.

Mooney, H.A. and S.L. Gulmon. 1992. Constraints on leaf structure and function in reference to herbivory. BioScience 32:198-206.

Moran, R. 1982. Formulae for determination of chlorophyllous pigments extracted with $N, N$-dimethylformamide. Plant Physiol. 69:1376-1381.

Ni, N., N.T. Watanabe, K. Yamaguchi, and M. Nishimura. 1995. Changes of anatomical features, photosynthesis and ribulose bisphosphate carboxylase-oxygenase content of mango leaves. Ann. Bot. 88:331-338.

Noguchi, K., K. Sonoike, and I. Terashima. 1996. Acclimation of respiratory properties of leaves of Spinacia oleracea L., a sun species, and of Alocasia macrorrhiza (L.) G. Don., a shade species, to changes in growth irradiance. Plant Cell Physiol. 37:377-384.

Pearcy, R.W., O. Björkmann, M.M. Caldwell, J.E. Keely, R.K. Monson, and B.R. Strain. 1987. Carbon gain by plants in natural environments. BioScience 37:21-29.

Priestley, C.A. 1977. The annual turnover of resources in young olive trees. J. Hort. Sci. 52:105-112.

Schaffer, B., A.W. Whiley, and R.R. Kholi. 1991. Effects of leaf age on gas exchange characteristics of avocado (Persea Americana Mill.). Scientia Hort. 48:21-28.

Shaper, H. and E.K. Charcko. 1993. Effect of irradiance, leaf age, chlorophyll content and branch-girdling on gas exchange of cashew (Anacardium occidentale L.) laves. J. Hort. Sci. 68:541-550.

Turgeon, R. and J.A. Webb. 1973. Leaf development and phloem transport in Cucurbita pepo: transition from import to export. Planta 113:179-191.

Turgeon, R. and J.A. Webb. 1975. Leaf development and phloem transport in Cucurbita pepo: carbon economy. Planta 123:53-62.

Turgeon, R. 1989. The sink-source transition in leaves. Annu. Rev. Plant Physiol. Plant Mol. Biol. 40:119-138.

Villar, R., A.A. Held, and J. Merino. 1994. Comparison of methods to estimate dark respiration in the light in leaves of two woody species. Plant Physiol. 105:167-172. 